\title{
Free Lunch
}

\section{ROBERT HESSEN}

'There's no such thing as a free lunch' dates back to the 19th century, when saloon and tavern owners advertised 'free' sandwiches and titbits to attract mid-day patrons. Anyone who ate without buying a beverage soon discovered that 'free lunch' wasn't meant to be taken literally; he would be tossed out unceremoniously.

'Free lunch' passed over into political economy during the New Deal era, and is loosely credited to various conservative journalists, including H.L. Mencken, Albert Jay Nock, Henry Hazlitt, Frank Chodorov and Isabel Paterson. (All efforts to identify the true originator proved unavailing.) The phrase signified that the welfare state is an illusion: government possesses no wealth of its own, so it can only redistribute wealth it has seized by taxation.

During the Vietnam war era, 'free lunch' took on a libertarian cast. When defenders of the draft argued that young men owed military service because they had accepted free tuition and subsidized school lunches as youngsters, the 'free lunch' expression became a libertarian shorthand to denote that citizens never get something for nothing, that sooner or later they are presented with a bill for all the favours or 'freebies' they accepted from government.

'Free lunch' would have passed into oblivion if it had not been able to pass a crucial test of its viability in the marketplace of ideas. In the early 1970s, every political or philosophical idea had to be able to fit on a T-shirt or automobile bumpersticker. The new version, TANSTAAFL (there ain't no such thing as a free lunch), was popularized in a science fiction bestseller by Robert Heinlein (The Moon is a Harsh Mistress) and in Milton Friedman's widely read columns in Newsweek magazine. 